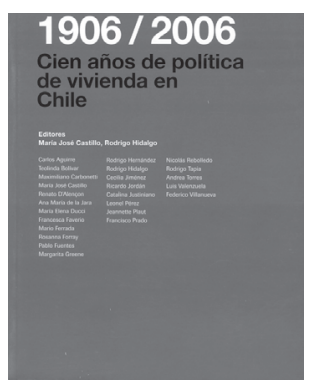

\title{
María José Castillo y Rodrigo Hidalgo (Editores). 1906/2006 Cien años de política de vivienda en Chile
}

\author{
Santiago de Chile: Facultad de Arquitectura y Diseño \\ de la Universidad Nacional Andrés Bello e Instituto \\ de Geografía de la Facultad de Historia, Geografía y \\ Ciencia Política de la Pontificia Universidad Católica \\ de Chile, 2007, 325 p.
}

Paloma Henríquez $\mathrm{Cid}^{1}$

Las políticas habitacionales de las últimas décadas del siglo XX en Chile han tenido como objetivo fundamental disminuir el déficit de viviendas, ya sea a nivel cuantitativo como cualitativo. Una forma de sanar este déficit fue a través de la construcción de viviendas sociales que pudieran aminorar el problema a las personas de más escasos recursos de la sociedad.

En 1965, con la creación del Ministerio de Vivienda y Urbanismo (MINVU), comenzó a existir una mayor preocupación en el establecimiento de políticas de viviendas y su relación con el desarrollo global de la ciudad. Así, la política habitacional propuesta para esa época tenía correspondencia con el marco de desarrollo económicosocial del país, el cual cumpliría con el principio de que la "vivienda es un bien de primera necesidad", al que tiene derecho toda familia humana y determinar, asimismo, el orden de las prioridades zonales, la ubicación urbana o rural de la vivienda además de precisar el nivel cualitativo de las construcciones (Hidalgo, 2005).

Hoy en día los programas habitacionales representan el conjunto de disposiciones con que opera el SERVIU; existen diversos programas que responden a las distintas necesidades de la población, entre ellos se encuentran: Subsidio Habitacional, Programa de Vivienda Social Dinámica sin Deuda, Sis-

1 Estudiante de Geografía que cursa su último año de carrera. E-mail: Phenriquez@geo.puc.cl tema de Movilidad Habitacional, Subsidio Leasing Habitacional, Subsidio Rural, Vivienda Progresiva, Atención Especial para Adultos Mayores, Programa Especial para Trabajadores (PET) y el Fondo Solidario de Vivienda (MINVU, 2006).

El estudio y análisis de las implicancias de las políticas habitacionales en Chile son tema de interés de un abanico multidisplinario de profesionales como arquitectos, geógrafos y urbanistas, entre otros. En este contexto, se realizó el Seminario "1906-2006, Cien años de política de vivienda en Chile", enmarcado en la XV Bienal de Arquitectura, el que se realizó entre el 10 y 12 de octubre de 2006 y fue convocado por destacados e importantes investigadores y académicos de la Pontificia Universidad Católica, Universidad Nacional Andrés Bello y la Universidad Central de Venezuela.

Esta obra es resultado de la recopilación de las ponencias de investigadores y académicos que participaron del Seminario 19062006, Cien años de política de vivienda en Chile". Entre ellos es posible encontrar una serie de artículos dedicados específicamente al tema habitacional, sus origines, evolución y nuevos desafíos, vistos desde el punto de vista geográfico y arquitectónico.

El primer capítulo del libro, titulado "El palimpsesto de la política de vivienda social", da cuenta de los orígenes de la vivienda social, las primeras medidas y decisiones que se tomaron en torno a esta y las consecuencias que fueron dando forma al territo- 
rio; mientras que en la segunda parte da cuenta del tema de la participación de los distintos agentes en el proceso de habitabilidad y la contribución que hacen los ciudadanos usuarios de programas habitacionales. Esto implica que se analizan los resultados obtenidos de las distintas experiencias que dan a conocer los autores, para luego identificar las debilidades y fortalezas de la participación y sus futuros desafíos frente a la política habitacional vigente. El tercer capítulo de libro tiene una directriz más arquitectónica, la cual presenta estrategias de recuperación y revitalización de conjuntos de vivienda social, enfocados a la repoblación de centros urbanos, mejoramientos de barrios y metodologías para la construcción de viviendas sociales. El cuarto capítulo da a conocer la experiencia internacional, específicamente la política habitacional de Venezuela y algunos ejemplos de América Latina y el Caribe en general.

Desde el ámbito de la Geografía, esta obra posee un valioso aporte para la comprensión y análisis de los impactos en el territorio de las distintas políticas habitacionales en Chile. A principios de siglo XX, debido a los cambios en los sectores políticos, económicos, sociales y culturales, se dio paso a un giro en la sociedad chilena, la cual generó nuevos horizontes en la población. De este modo, surgen las primeras políticas habitacionales para destituir al "conventillo", que era caracterizado por el hacinamiento y la insalubridad. Es la Ley de Habitaciones Obreras de 1906 la encargada de solucionar esta problemática, si bien esta fue la primera instancia para hacer frente al déficit de viviendas, no fue capaz de solucionarlo, ya que no se logró llegar a las clases más pobres. Años más tarde, en 1936, se crea la Caja de Habitación Popular, que tenía como finalidad la búsqueda de una casa y una ciudad modelo. La Caja operó por largo tiempo y tuvo gran relevancia en la evolución del tejido urbano y, por lo tanto, en la conformación de la ciudad.

La expansión de la ciudad era tal, que para los años sesenta no solo la ciudad de Santiago estaba expandiéndose a ritmo acelerado, sino que otras ciudades como Concepción también estaban dentro de la lógica de crecimiento poblacional y urbanístico.
En 1965, con la creación del Ministerio de Vivienda y Urbanismo, el tema habitacional adquirió mayor importancia y pasó a tener relevancia nacional, destacándose la promoción de diferentes programas habitacionales que estaban destinados a las personas con menos recursos. Frente al sostenido aumento de la población, la cuidad superó todos los límites establecidos; en algunos casos fueron los proyectos de vivienda social que pasaron a ocupar terrenos en la periferia de la ciudad, obligando el crecimiento hacia fuera. Hacia 1990 el cambio en la economía del país permitió generar un gran impulso en la construcción de soluciones habitacionales que tomaban en cuenta vivienda, educación y salud, dentro de una visión más integral.

Las políticas habitacionales durante los últimos 16 años han tenido como principal objetivo la eliminación del déficit cualitativo y cuantitativo de la vivienda social, además del mejoramiento paulatino de las condiciones de habitabilidad de las familias. En este sentido, la nueva política habitacional, creada en el año 2002, se basó principalmente en refocalizar los programas que atienden a los sectores más pobres de la población. Respecto de ello, se menciona en el libro que los tres componentes básicos de la política habitacional chilena son: el ahorro, el subsidio estatal a la demanda y el crédito hipotecario. Teniendo en cuenta que las familias tienen poca capacidad de endeudamiento, se delega en el usuario la construcción de una parte de su vivienda bajo el concepto de "ampliación", que es un supuesto central para la factibilidad y habitalidad de las viviendas. Sin embargo, y debido al resultado del proceso de diagnóstico que se realizó durante los años 2000 y 2001, se modifico el PVP, puesto que consumía más de la mitad del presupuesto del MINVU, esto llevó a la creación del Programa de Vivienda Social Dinámica sin Deuda (PVSDSD), que tuvo mayores restricciones a su acceso, buscando evitar que familias relativamente menos pobres accedieran al subsidio (Cámara Chilena de la Construcción, 2004).

El desarrollo de las distintas políticas o programas habitacionales no solo repercutió en el mejoramiento de la vivienda y la solu- 
ción habitacional, sino que también tuvo importantes impactos en el territorio.

Producto de la nueva organización de la ciudad, en donde la localización de la vivienda social se traslada a los barrios periféricos, surgen nuevas patologías urbanas ligadas a la pobreza urbana y la marginalidad. La pobreza no es la misma de cien años atrás; las distintas intervenciones políticas en materia de vivienda y la evolución en el sistema económico han llevado a que la pobreza también evolucione, esto se traduce en que la nueva pobreza se refiere al lugar donde se vive, y el tipo de vivienda al que se pudo tener acceso. La dinámica territorial en los últimos años de la vivienda social está dada por el precio del suelo, por esto es que los conjuntos de vivienda social se emplazan en aquellos terrenos con menor valor, los cuales ya tienen una tendencia a la segregación territorial y social, puesto que se fusionan distintos elementos en un mismo territorio sin una ordenación adecuada. El resultado de esta metamorfosis es una ciudad de dinámica reticular, caracterizada por la persistencia de una polarización de lejano origen, que redunda en la intensificación de la segregación residencial, y por una continuada dilatación dispersa y discontinua, que origina una mancha urbana de estructura policéntrica y fronteras móviles, que desborda y desdibuja continuamente sus límites y cuyo paisaje está marcado por la aparición fragmentaria de un conjunto de artefactos que juegan un papel central en la estructuración del espacio urbano (De Mattos, 1999).

Se configura entonces una ciudad de Santiago con una extensión hacia las zonas periféricas. Por otro lado, se observa un despoblamiento en las zonas urbanas, lo que ha obligado a tomar ciertas medidas para que el crecimiento futuro sea densificado. En esta línea, el Ministerio de Vivienda y Urbanismo ha creado subsidios habitacionales para la compra de viviendas en sectores de renovación, la idea es renovar y repoblar la comuna de Santiago, recuperando su rol residencial e identidad barrial, además de reconstruirlo como un centro urbano metropolitano atractivo. Esta es otra medida habitacional, que si bien no está relacionada directamente con la vivienda social, trata de paliar el déficit de habitacional dentro de los límites de la ciudad.

Cabe preguntarse cómo nuestra labor de geógrafos puede contribuir al mejoramiento de la ciudad: nuestro deber es abrirnos paso en la ordenación y futura planificación de la ciudad, y ayudar al territorio y la población para una coexistencia positiva y eficiente.

\section{Referencias bibliográficas}

CÁMARA CHILENA DE LA CONSTRUCCIÓN. Subsidio vivienda pública: alcances al presupuesto 2005. Santiago de Chile: CCHC, 2004.

DE MATTOS, C. Globalización y Metropolización en Santiago de Chile: Una Historia de Continuidades y Cambios. En: MINISTERIO DE PLANIFICACIÓN Y COOPERACIÓN UNIVERSIDAD ALBERTO HURTADO. Metropolización en Chile, interrogantes y desafíos. Santiago de Chile: Ministerio de Planificación y Cooperación, Universidad Alberto Hurtado, 1999, p. 25-63.

HIDALGO, R. La Vivienda Social en Chile y la Construcción del Espacio Urbano en el Santiago del siglo XX. Santiago de Chile: Pontificia Universidad Católica de Chile, Instituto de Geografía, Ediciones GEOlibros, 2005.

MINISTERIO DE VIVIENDA Y URBANISMO - MINVU. Encuesta de Satisfacción Residencial. Santiago de Chile: MINVU, 2002. Disponible en Internet: www.minvu.cl. 